\title{
NEUROBLASTOMA IN ORTHOPAEDIC PRACTICE
}

\author{
P. I. Busfield, London, ENGLAND
}

\author{
From the Department of Surgery, Postgraduate Medical School, London
}

This paper is intended to bring attention to the frequency with which cases of neuroblastoma may present as orthopaedic problems. The subject has attracted little attention in orthopaedic literature. Recent advances in treatment, with an improvement in the prognosis, justify a review of the orthopaedic aspects of the disease.

\section{PATHOLOGY}

Neuroblastoma is a malignant tumour arising from cells which have their origin in the neural crest. In the early embryo cells migrate from the region of the developing spinal cord to form the ganglia of the sympathetic nervous system and the medulla of the adrenal glands. Neuroblastoma most commonly arises in the adrenals, but it may also arise in sympathetic tissue behind the peritoneum, in the posterior mediastinum, or in the neck.

The histological appearances of the tumour vary with the degree of differentiation. The undifferentiated tumour consists of cells which are of uniform appearance, with scanty ill-defined cytoplasm and a single spherical nucleus. Mitotic figures may be numerous, and there are no nerve fibrils. Identification of the undifferentiated tumours may be difficult, and they were formerly interpreted as sarcomata. When partly differentiated the cells develop small fibrils and tend to become arranged in a characteristic rosette. Willis (1953) described the complete rosette as an arrangement of twenty or thirty cells with their nuclei at the periphery, surrounding a central area in which are contained the fibrils from each cell. It can be demonstrated that each fibril represents a small axon cylinder in continuity with the cytoplasm of the parent cell; the axon is non-myelinated and there are no neurilemmal cells. Complete differentiation is seen in the benign ganglioneuroma. This tumour contains adult nerve cells with mature nerve fibres which may be sheathed in neurilemma.

The gross appearance of the tumour is also variable. The adrenal neuroblastoma often appears to be confined within a capsule, showing no tendency to local infiltration. Less commonly there is widespread infiltration into the surrounding tissues. A remnant of the adrenal cortex may still be visible. Large areas of haemorrhage into the substance of the tumour are common, and calcification can often be demonstrated.

The tumour metastasises by the lymphatic route and by the blood stream. The paravertebral glands become extensively involved in abdominal neuroblastoma, and from there the tumour may infiltrate directly into the vertebral bodies. There may be extensive involvement of the cervical, axillary and inguinal lymph nodes. Haematogenous spread occurs most often in the liver, which may be grossly enlarged by discrete secondary deposits. Metastases have been recorded in all bones except those of the hands and feet, but they are most often found in the skull, pelvis, spine and the long bones. They occur occasionally in the skin. Gross involvement of the lungs is uncommon.

The standard text-books emphasise two clinical syndromes which have become the classical presentation of neuroblastoma. The Pepper syndrome comprises a primary adrenal tumour with metastases in the liver. The Hutchinson syndrome is produced by secondary deposits in the orbit and the skull. The literature of the last five years confirms that this presentation is incomplete. An analysis of the cases reported shows that a considerable proportion include features of particular concern to orthopaedic surgeons. 


\section{DISTRIBUTION AND INCIDENCE}

The clinical series reported in the last five years have been reviewed. There were 177 cases of neuroblastoma in which the site of the primary tumour was stated. They were distributed as follows: 1) retroperitoneal primary 135 (76 per cent); 2) intrathoracic primary eighteen $(10.2$ per cent $) ; 3)$ primary in the neck nine $(5 \cdot 1$ per cent $) ; 4)$ primary elsewhere fifteen ( 8.5 per cent). These last include a variety of sites - the pelvis, the naso-pharynx, the central nervous system and the internal ear.

There were ninety-six patients with neuroblastoma in which the sex of the patient was stated. They were equally divided-forty-eight were male and forty-eight female.

There were 104 patients with adrenal neuroblastoma in which the side of the primary tumour was stated. Sixty (57.7 per cent) were on the right side and forty-four ( 42.2 per cent) on the left. This is not statistically significant.

In no case was the primary tumour bilateral. In ninety-six cases the age of the patient was stated. Fifty-two (54.2 per cent) were under two years. Most of the others were children under ten years. The disease is rare in adults but several cases have been reported.

\section{DIAGNOSIS}

In any uncommon disease the presenting symptoms are of particular importance because they will usually determine to which hospital department the patient will be referred. This in turn will allocate the responsibility of diagnosis, a responsibility that is heaviest when early diagnosis can influence the outcome of the disease.

In the series reviewed there were 106 cases in which the presenting symptoms were recorded. They fall into four distinct groups.

Group 1. Abdominal (fifty-one-cases-47 per cent)-Attention was immediately directed to the abdomen. Abdominal pain, distension and vomiting were the commonest symptoms. In some patients a mass was felt on routine examination. A few presented with abdominal pain which resembled acute appendicitis.

Group 2. Orbital (nine cases-8.5 per cent)-In these patients the presenting symptoms were proptosis of one or both eyes, spontaneous haemorrhages into the eyelids, or deterioration in vision.

Group 3. General (twenty-six cases-24 per cent)-Here the presenting features were the general symptoms of malignant disease in childhood. These symptoms include lethargy, loss of weight and a diminishing appetite and energy. Unexplained pyrexia and a mild anaemia were commonly present.

Group 4. Orthopaedic symptoms (twenty-four cases-22.5 per cent)-In these patients the presenting symptoms were such that the advice of an orthopaedic surgeon might have been sought. They included pain about a joint, usually in the lower limbs; an unexplained limp or a disinclination to walk; acute pain in a bone, with signs resembling acute osteomyelitis; backache; and the development of paraplegia.

It appears from this analysis that almost a quarter of the patients with neuroblastoma will present as orthopaedic problems. It is characteristic of malignant disease in children that the early symptoms may regress spontaneously. Furthermore, when orthopaedic symptoms first appear they may not be accompanied by any radiological abnormality. The diagnosis is usually not suspected until either proptosis or a palpable abdominal tumour appears, and a number of weeks may pass before either of these is noticed. These circumstances combine to make early diagnosis difficult unless the condition is suspected and a full investigation carried out on suspicion alone.

Clinical examination-The detection of an abdominal swelling is the most important physical sign. The swelling may be due to the primary tumour, to the displaced kidney or to enlargement of the liver. It may be high under the costal margin and difficult to feel, or it may be a mass which almost fills the abdomen. Ascites is occasionally present, and there may be engorgement 
of the veins of the abdominal wall. Vena caval obstruction may lead to oedema of the lower limbs. The eyes should be closely examined for proptosis, and the lids and conjunctivae for areas of haemorrhage. Palpation of the scalp may reveal subperiosteal nodules. A full neurological examination is important, with particular reference to power, sensation and reflexes in the lower limbs.

The axillary, cervical and inguinal lymph nodes should be palpated.

Special investigations. Radiography of the abdomen-There may be a soft-tissue shadow caused by the tumour or by the displaced kidney. Calcification commonly occurs in the tumour and may be demonstrable radiologically. It may appear as fine speckling in the suprarenal area or as a dense radio-opacity. The diaphragm may be elevated by the tumour or by the enlarged liver.

Pyelography-This is the most important single investigation. Usually it shows displacement of the renal pelvis downwards and laterally. Occasionally the pelvis is distorted by invasion of the kidney. Rarely there may be ureteric obstruction and hydronephrosis.

Radiography of chest-This may show a tumour in the posterior mediastinum or metastases in the lung fields. Secondary deposits may be seen in the ribs. In a "dumb-bell" tumour there may be destruction of vertebral transverse processes and adjacent parts of the ribs.

Radiography of long bones-Secondary deposits are usually osteolytic, and may be bilateral and symmetrically placed in the region of the metaphyses. Subperiosteal new bone may be laid down in laminated " onion-skin " layers. Occasionally there may be extensive localised destruction leading to pathological fracture.

Radiography of the skull-The calvarium may be stippled with areas of increased transradiance. Subperiosteal new bone may be laid down perpendicularly to produce " sun-ray " spiculation. Intracranial extension may cause increased intracranial pressure and widening of the sutures. Examination of the blood-A mild anaemia is often present early in the disease. Severe anaemia suggests extensive involvement of the marrow. Leucocytosis is not uncommon. The white cell count was above 10,000 in three of the ten cases recorded in the Survey of Cancer in London (Harnett 1952).

Erythrocyte sedimentation rate-The only reference to an increase in the sedimentation rate is by Gross (1955). This is an important investigation which may give early warning of the sinister background to an apparently innocent symptom. It was elevated at some stage in each of the cases reported here and was an important early feature in Case 2.

Histological study of material obtained by sternal marrow puncture-This occasionally demonstrates tumour cells when the marrow is extensively involved. It has also been used to follow the effect of chemotherapy on metastases of microscopic size.

Histological study of biopsy specimens-This is not an infallible investigation. Considerable difficulty may be encountered in identifying an anaplastic tumour, and a haemorrhagic area may fail to yield malignant cells.

It has been our experience, and is the impression given by many of the cases reviewed, that when a patient presents with orthopaedic symptoms general examination usually does not reveal any reason to suspect the diagnosis. There are a few clinical syndromes which should immediately arouse suspicion. A case of seeming osteomyelitis with comparatively little elevation in the white cell count, with mild anaemia and a raised sedimentation rate, should suggest neuroblastoma. The development of paraplegia in a child, with no radiological changes in the spine, means that neuroblastoma must be excluded. Spontaneous haemorrhages along the margins of the eyelids warrant extensive investigation.

\section{CASE REPORTS}

Case 1-A boy aged eleven years presented in 1956 with a history of pain in the lumbar region which had started a few weeks before. About the same time it was noticed that bruising appeared spontaneously in the right upper eyelid. He began to walk with a limp and his parents

VOL. $40 \mathrm{~B}$, NO. 1, FEBRUARY 1958

D 
noticed that he seemed to tire easily. On first examination it was noted that there was some wasting of the right quadriceps; the right knee-jerk was absent, and there was an area of impaired sensation below the right knee. There were no other physical signs, and radiographs of the thoracic and lumbar spine appeared normal.

Two months later proptosis of the right eye was noticed and the lower pole of the right kidney became palpable. By that time extensive paresis of the right lower limb and anaesthesia over the third, fourth and fifth lumbar dermatomes had appeared. The intravenous pyelograph showed a deformity of the right renal pelvis. Sternal marrow smear was suggestive of neuroblastoma.

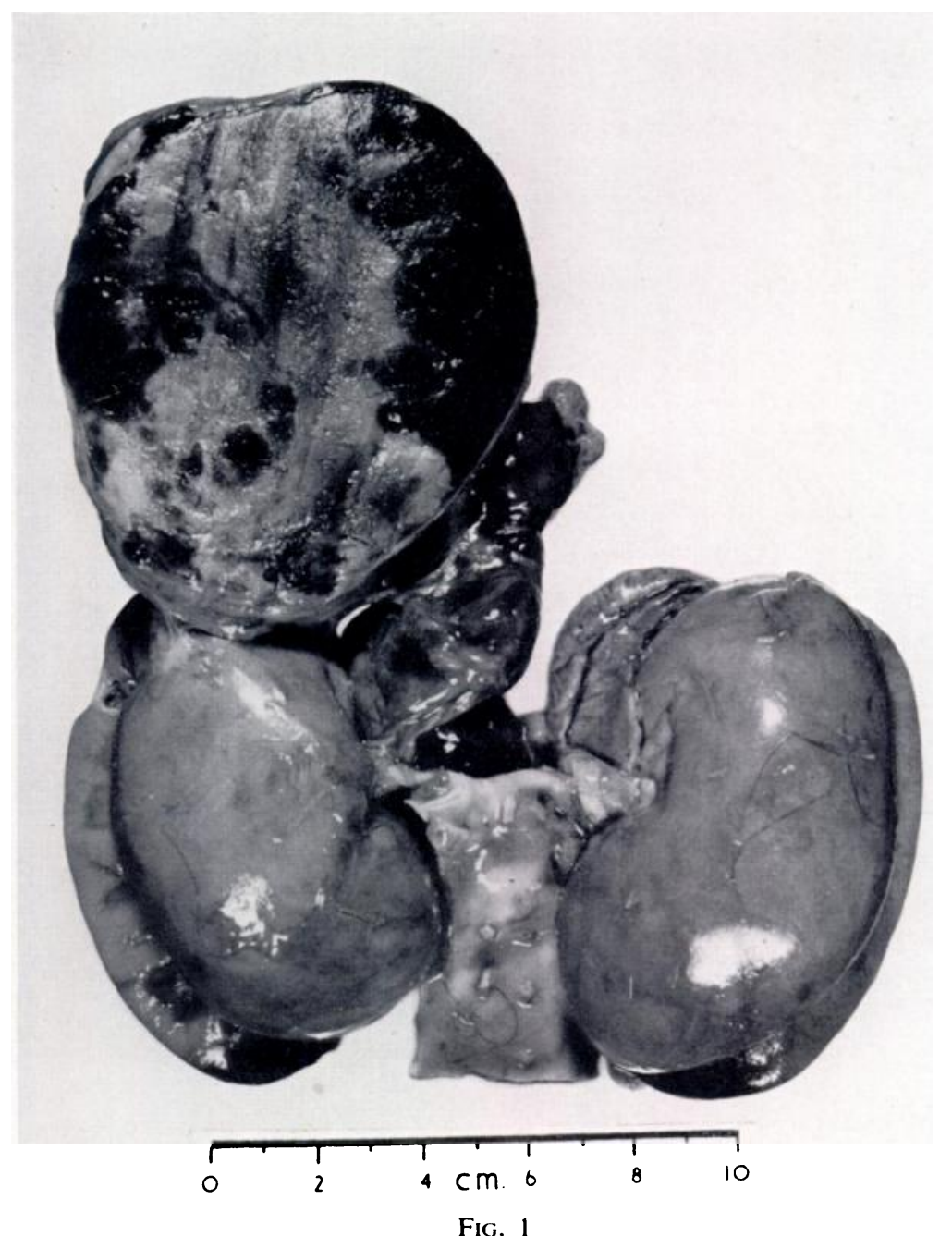

Case 1 -The primary tumour. The tumour has been cut across and the kidneys bisected. The tumour appears to be encapsulated and there are numerous areas of haemorrhage. Some of the involved para-aortic glands are shown in the specimen.

After a further month the patient had a complete flaccid paraplegia with anaesthesia below the fifth thoracic level and a paralysed bladder. The sedimentation rate was then 70 millimetres in the first hour. The haemoglobin was 52 per cent and the white cell count was 4,200 per cubic millimetre. Radiographs of the skeleton showed widespread deposits in both humeri and femora, and in the pelvis, but no evidence of vertebral metastases.

Irradiation was given to the region of the right orbit. There was a severe reaction which resulted in opacity of the cornea, but the proptosis subsided. A course of oral and intravenous radioactive phosphorus was given but no response was apparent. His general condition deteriorated despite 
repeated blood transfusions and he died seven months after the onset of symptoms. The diagnosis was confirmed at necropsy. The primary tumour is shown in Figure 1.

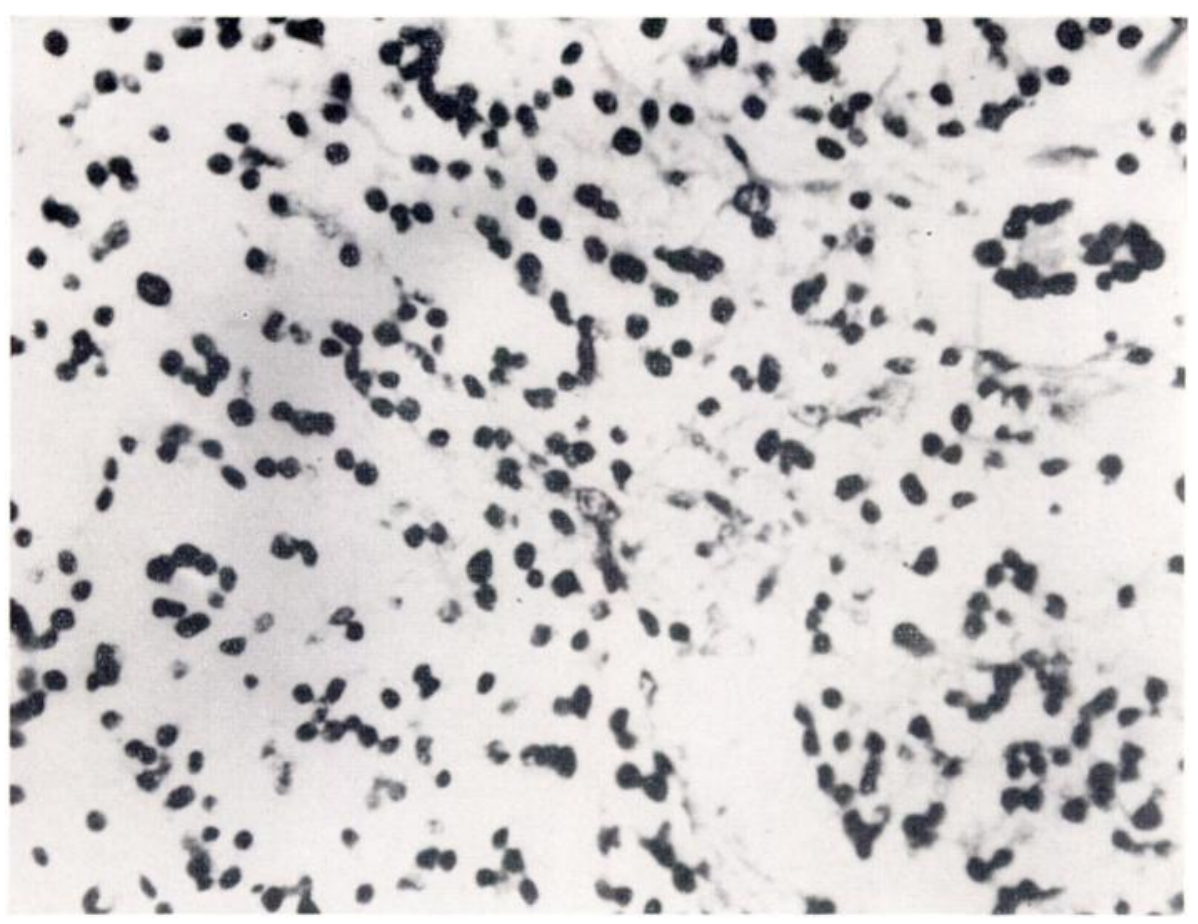

FIG. 2

Case 2 -Section of the primary tumour showing the incomplete formation of rosettes.

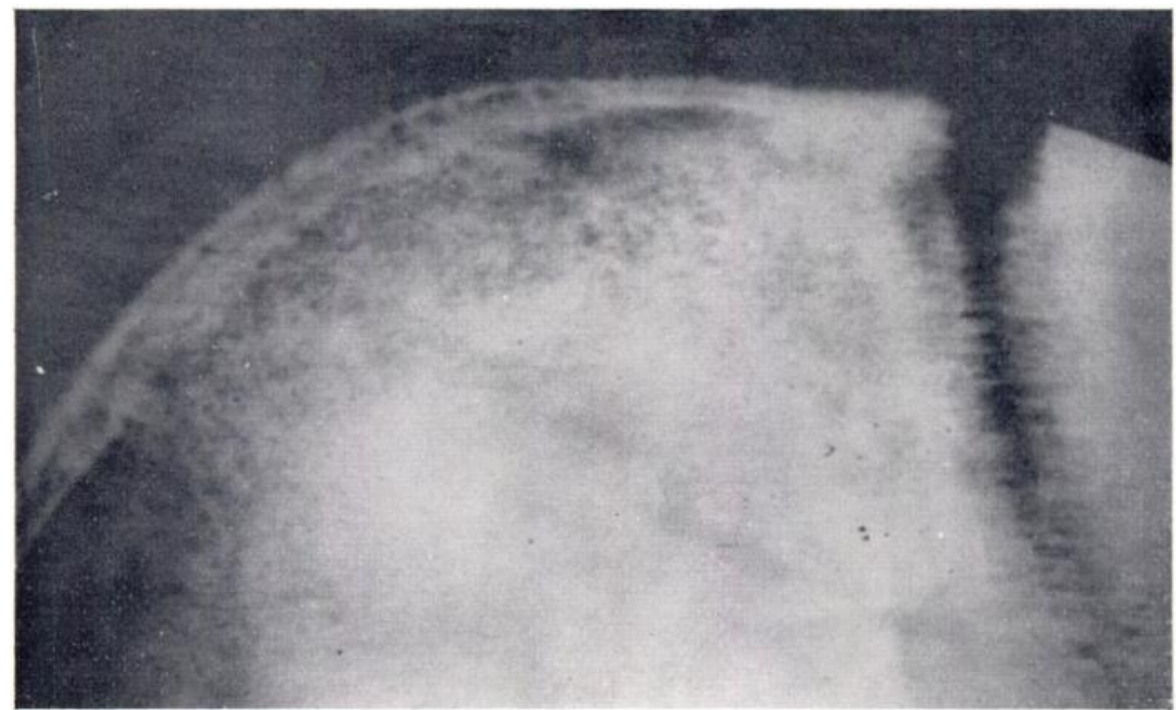

FIG. 3

Case 2-Part of the radiograph of the skull. This demonstrates the "stippling " of the calvarium, the formation of " sun-ray " spicules and widening of the sutures, which together are diagnostic of neuroblastoma.

Case 2-A boy aged five years presented in 1955 with a history of pain in the left hip which was attributed to a blow sustained a few days before. Examination at that time showed tenderness over the front of the hip joint and slight limitation of rotation. There were no other physical signs.

VOL. $40 \mathrm{~B}$, NO. 1, FEBRUARY 1958 
The Mantoux reaction was negative. The haemoglobin was 70 per cent and the white cell count was 10,000 per cubic millimetre. The sedimentation rate was 45 millimetres in the first hour. Radiographs of the hip were normal.

The hip was treated by continuous traction and the physical signs disappeared. There was, however, evening pyrexia, on occasions to 101 degrees Fahrenheit, and the sedimentation rate remained high. His general condition slowly deteriorated, and he began to complain of pain and stiffness in the neck. The left knee became painful and swollen, but there was no abnormality on the radiographs. He developed fleeting pains in other joints, and rheumatic fever was suspected. His symptoms appeared to subside with a course of salicylates, but the sedimentation rate remained over $\mathbf{4 0}$ millimetres.

Five months later a swelling was noted in the scalp, and biopsy of this enabled the diagnosis of neuroblastoma to be established. He rapidly developed numerous swellings in the scalp and generalised enlargement of cervical, inguinal and axillary lymph nodes. Irradiation was attempted, but was

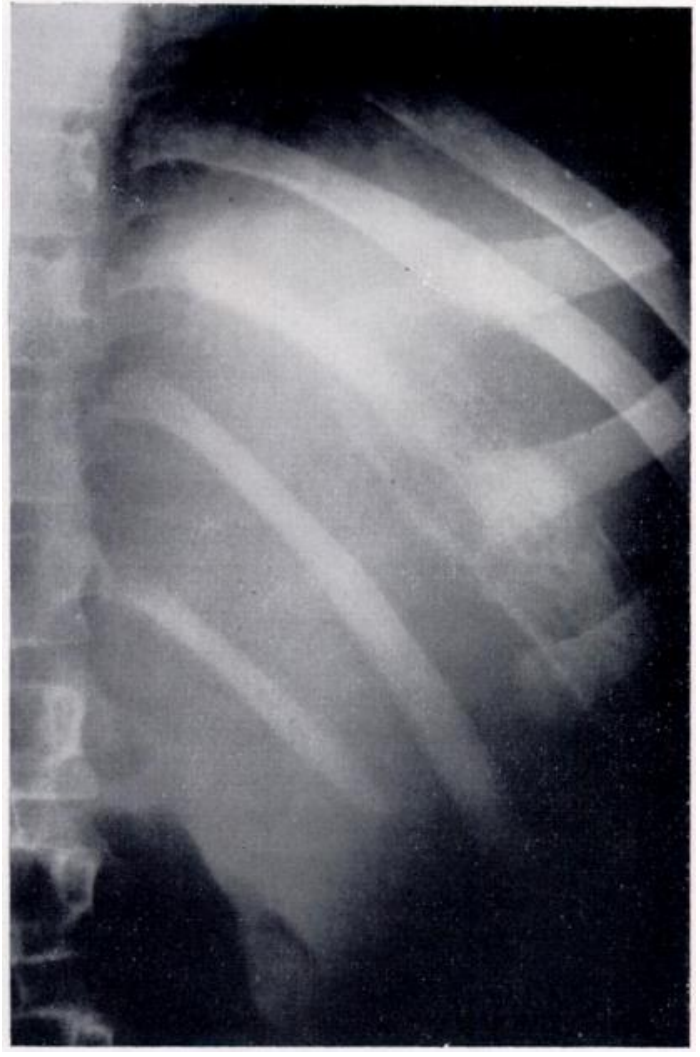

FIG. 4

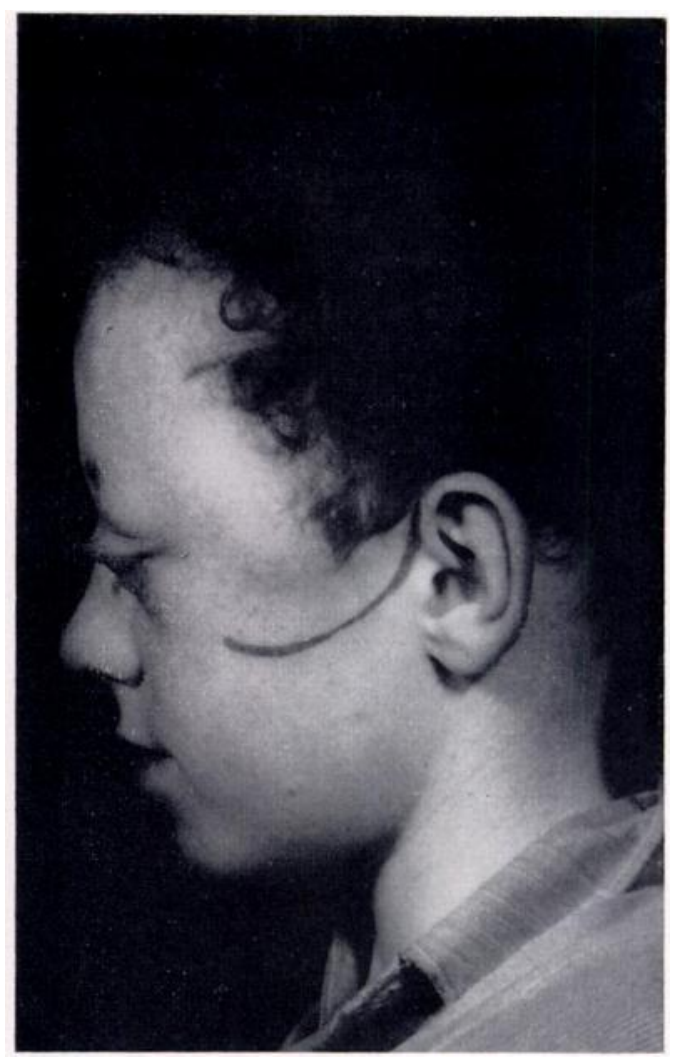

FiG. 5

Case 3. Figure 4-Radiograph of the right lower ribs. There is marked subperiosteal new bone formation. Figure 5-Photograph showing the temporal swelling and proptosis.

discontinued because the general condition rapidly deteriorated. A course of Vitamin B 12 was started but the boy died three weeks later, seven and a half months after the onset of symptoms. A small mass became palpable in the left hypochondrium two weeks before his death. The diagnosis was confirmed at necropsy (Figs. 2 and 3 ).

Case 3-A boy aged twelve years presented in 1956 with a painful swelling over the right lower ribs which he attributed to an injury sustained a few weeks before. Radiographs showed extensive destruction of the tenth rib with subperiosteal new bone, and also a small pleural effusion (Fig. 4). The condition was regarded as osteomyelitis and treated with a course of penicillin. There was rapid improvement, but within a few weeks the swelling returned larger than before. Biopsy was performed three months after the onset of symptoms. The histological appearances appeared to confirm the diagnosis of osteomyelitis, and treatment was continued with acromycin. The sedimentation rate rose to 127 millimetres in the first hour, and later a swelling was noted on the lateral aspect of the left orbit. A further biopsy enabled the diagnosis of neuroblastoma to be made. 
The patient subsequently developed generalised bone metastases and enlargement of the liver. Palliative irradiation was given. He died eight months after the onset of symptoms (Figs. 5 and 6 ). Case 4-Boy aged five years. This boy presented in 1951 with a history of pain in the right arm of four days' duration. Examination at that time showed tenderness and thickening over the middle of the shaft of the humerus, with increase in local heat. General examination showed no other abnormality. The temperature was normal. The haemoglobin was 80 per cent and the white cell count was 8,500 per cubic millimetre. The sedimentation rate was 20 millimetres in the first hour. The radiographs showed a little patchy rarefaction with no periosteal reaction.

Open biopsy was carried out. The bone was found to contain material which resembled thick, yellow pus. The histological appearance suggested secondary neuroblastoma. Soon a swelling became palpable in the abdomen, and the intravenous pyelograph demonstrated downward displacement of the right kidney.

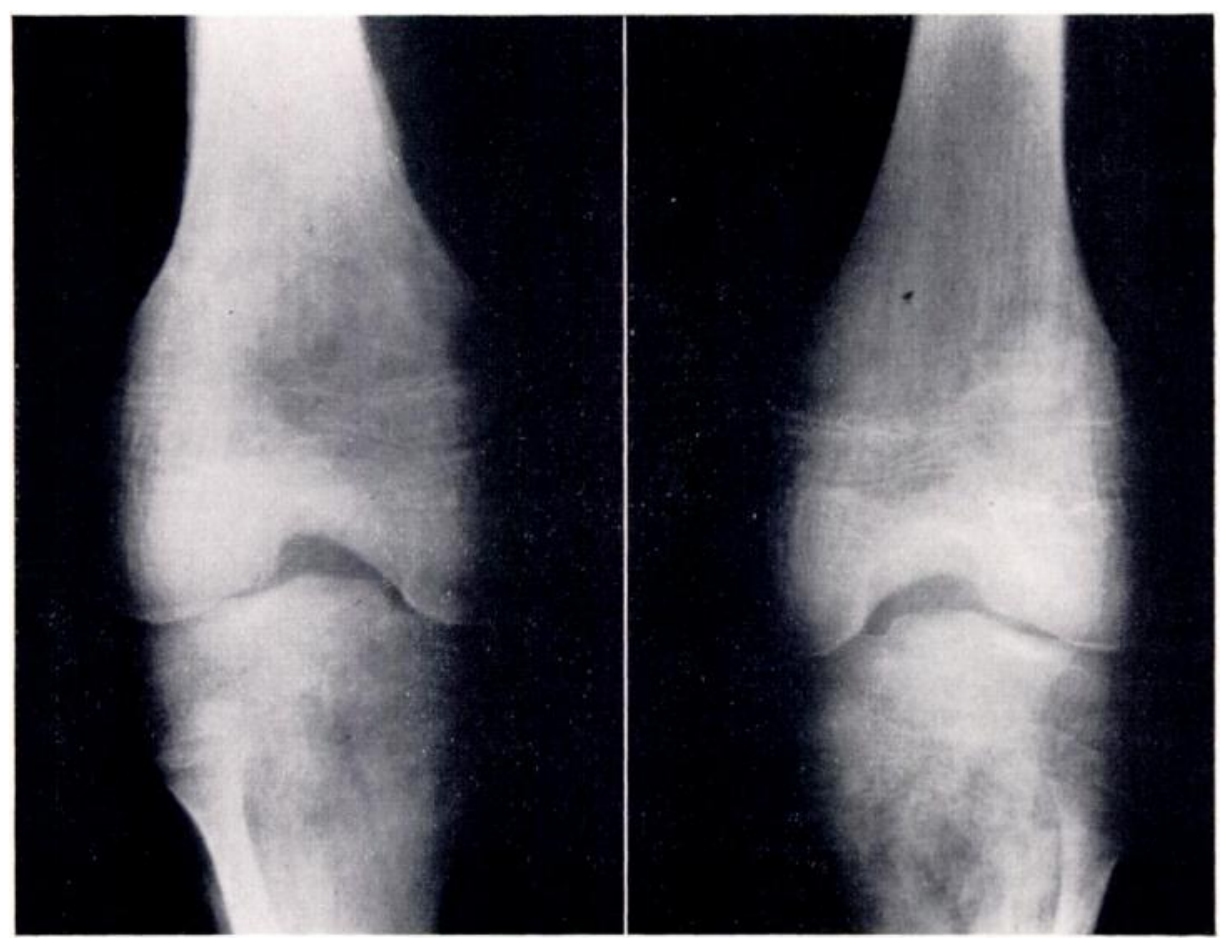

FIG. 6

Case 3. Radiographs showing the characteristic arrangement of bone metastases in neuroblastoma. The metastases may be bilateral, symmetrical and situated in the region of the metaphyses. They usually appear late in the disease.

The lesion in the humerus extended and pathological fracture occurred. Palliative irradiation was given. The child died nine months after the onset of symptoms.

Case 5-A girl aged sixteen years presented in 1955 with a history of pain over the anterior part of the left iliac crest; this had been increasing in severity over the previous three months. She had sustained a minor injury to the inguinal region on the same side a few weeks before the onset of the pain. Before admission to hospital she had been treated with penicillin without improvement.

Examination at that time showed tenderness over the anterior inferior iliac spine. The radiographs demonstrated a little subperiosteal new bone in the area of tenderness. The patient was treated with continuous traction and a course of streptomycin, and her symptoms improved. The sedimentation rate was persistently raised to between 30 and 40 millimetres in the first hour. The white cell count varied between 6,000 and 12,000 per cubic millimetre. Her temperature remained elevated, on occasions to 100 degrees Fahrenheit.

A month later she was transferred for further investigation. There was now a tender swelling on the outer aspect of the left ilium. The radiographs showed increased new bone formation, with underlying areas of increased density and rarefaction. The sedimentation rate was now 90 millimetres 
in the first hour, and the haemoglobin was 88 per cent. There were no other physical signs. Radiographs of other bones showed no abnormality.

Open biopsy was performed and histological examination of the specimen established the diagnosis of neuroblastoma. The intravenous pyelograph appeared to be normal. Palliative irradiation was given to the ilium, with considerable symptomatic relief, and she was allowed to return home. She died eight months after the onset of symptoms. The necropsy showed widespread metastases, and the primary tumour appeared to have arisen in the posterior mediastinum.

Case 6-Boy aged twelve years. This boy presented in 1951 with a history of pain and swelling in the right thigh which had started four months before. The pain had been intermittent but the swelling had slowly increased in size. Examination at that time showed a diffuse, hard swelling attached to the lowest third of the femur. There were no other physical signs. The radiographs showed a tumour in the soft tissues, and underlying this an area of subperiosteal new bone which was laminated. The appearance suggested either an osteogenic sarcoma or a Ewing's tumour. The haemoglobin was 71 per cent and the white cell count was 9,300 per cubic millimetre. The sedimentation rate was 25 millimetres in the first hour.

Open biopsy was performed and the histological appearance suggested either a Ewing's tumour or a secondary neuroblastoma. Radiographs of the rest of the skeleton showed no evidence of other metastases. The intravenous pyelograph showed that the left kidney was slightly displaced downwards. There was slight hydronephrosis but no distortion of the calyces. The twelfth rib on the same side was completely destroyed.

Because of the size of the secondary tumour in the femur amputation was performed through the upper third of the thigh. The patient made a good recovery and was symptom-free until a year later, when further lesions appeared in the mandible, the scalp and around the left knee. Radiographs of the abdomen now showed calcification in the left suprarenal area, destruction of the adjacent transverse processes and an area of calcification extending along the left side of the lower thoracic vertebral bodies. He died one year and nine months after the onset of symptoms.

\section{DIFFERENTIAL DIAGNOSIS}

The diagnostic problem presented to the orthopaedic surgeon is usually that of a local condition in bone combined with non-specific general manifestations. The conditions which have to be excluded fall into two groups: 1) local bone disease with general manifestations; and 2) general disease with localised manifestations in bone. Although the list of theoretical possibilities would be a long one, the conditions which, in practice, have to be differentiated are few.

Local bone disease. Osteomyelitis-The commonest difficulty arises when inadequate treatment with antibiotics has been given, with some apparent improvement. The association of a lowered haemoglobin with a raised sedimentation rate should lead to intensive investigation, including open biopsy, rather than a clinical trial with a different antibiotic.

Ewing's tumour-To avoid entering discussion on the pathogenesis of this tumour let it suffice to say that it may be difficult to differentiate between a primary tumour in bone and an apparently solitary metastasis from a neuroblastoma. It is important in such a case to obtain radiographs of the rest of the skeleton. Pyelography will often establish the diagnosis in adrenal neuroblastoma.

Osteogenic sarcoma-Although there may be some constitutional disturbance in bone sarcoma this is not usually as marked as in neuroblastoma. Skeletal radiographs, pyelography and biopsy will usually distinguish these tumours.

"Occult" tuberculosis-The early stages of bone tuberculosis, before radiographic changes are marked, may be difficult to distinguish from neuroblastoma. If the diagnosis is still in doubt after full investigation biopsy should be preferred to a clinical trial with streptomycin. Generalised diseases. Rheumatic fever-Neuroblastoma may closely simulate the fleeting joint pains of rheumatic fever without radiographic changes in the early stages. A persistently raised sedimentation rate, despite symptomatic improvement, may be the only early sign.

Aleukaemic leukaemia - The distinction may be difficult in cases of neuroblastoma with early involvement of superficial lymph nodes. Sternal marrow puncture may afford the only conclusive proof. 
TREATMENT AND PROGNOSIS

The treatment of neuroblastoma may be considered under three headings.

Surgery-Most authors in the series reviewed favoured a surgical attack on the primary tumour whenever practicable. The surgical ideal of excision of the primary growth with its regional lymphatic field is seldom possible. Good results are claimed in the cases in which it has been possible. Koop, Kiesewetter and Horn (1955) found six such cases in their series of thirty-nine and claimed that all have been cured. The proportion of their cases without distant metastases is unusually high.

There is wide difference of opinion on the procedure to be adopted when laparotomy shows that complete excision is impossible. In most cases only a biopsy specimen has been taken. Koop, Kiesewetter and Horn (1955) performed what they described as a " major surgical insult " to the tumour, removing as much as they could without regard to the accepted principles of cancer surgery. They claimed twelve cures out of thirty-nine cases.

Poore, Dockerty, Kennedy and Walters (1951) recorded a case in which there was lymphatic extension beyond the limits of excision, and in which they had to divide the inferior vena cava to remove the primary tumour. This patient has now survived for several years. Irradiation-Deep x-ray therapy has been used to effect cure, as a post-operative prophylactic, and as a palliative. The tumour is usually radio-sensitive, and often remarkably so. Phillips (1953) delivers $2,000-3,000 \mathrm{r}$. over ten to twenty days to destroy an adrenal tumour. Uhlmann and von Essen (1955) record six three-year survivals out of twenty cases treated (30 per cent).

Irradiation is not without danger. Radiation nephritis is a recorded complication when high dosage is given, and one fatal case has been reported. Depression of marrow function has led to cessation of treatment in several cases, and has caused one death.

Opinion appears to be divided about the value of post-operative irradiation. Wittenborg (1950) reviewed seventy-three cases in which the treatment was by operation, irradiation or both. Twenty-two of the patients survived for three years or more. In all the survivors the disease was confined to the abdomen.

Chemotherapy-The results already quoted are unfortunately of little more than theoretical interest to orthopaedic surgeons because the patients they see will usually present with bone metastases. In almost all the cases reviewed those with bone involvement have died, and survivals have been rare in the past. Hansen (1953) reported a patient who had bilateral proptosis and a deposit in the mandible, who was treated with irradiation alone, and who was well after twelve years. Goldring (1951) reported a case in which bilateral proptosis was combined with multiple metastases in liver and bone. The primary tumour alone was irradiated. The child was alive fifteen months later; the bone secondaries had disappeared and the proptosis subsided.

The only form of treatment that offers hope of success in cases with bone involvement is some kind of chemotherapy. A number of substances have now been used. Nitrogen-mustard has been tried extensively without much success. Some authorities claim that it has a particular effect on secondaries of microscopic size. It may be given intravenously $(0.4$ milligram per kilogram of body weight). Folic acid antagonists have been used in recent years with some success. Phillips (1953) recommended amethopterin ( 2.5 milligrams daily for ten days) in repeated courses with intervals of fourteen days.

Interest has recently been centred on the use of vitamin B 12, which has been used at the Hospital for Sick Children, Great Ormond Street, for the last four years. The preliminary reports show that a quarter of the patients survived for more than two years without recurrence. In other cases there has been some improvement and a fatal issue has been delayed. The patients selected for treatment usually had widespread disease and could not otherwise have been expected to survive. One milligram of vitamin B 12 is given on alternate days and the dosage is maintained for two years or more. Dr Martin Bodian is preparing a detailed account of his experience with this form of treatment.

VOL. $40 \mathrm{~B}$, NO. 1, FEBRUARY 1958 


\section{DISCUSSION}

It seems that the principles of treatment in neuroblastoma are becoming established. The usual aim in all the recent series has been to attack the primary tumour even in the presence of metastases. It is widely felt that the primary tumour has some influence on the rate and extent of secondary spread, and that the metastases are more responsive to treatment when the primary has been controlled in some way.

A good deal of attention has been directed to the spontaneous "maturation" of the malignant neuroblastoma into the benign ganglioneuroma. A small number of cases have now been reported of prolonged survival when no active treatment has been given. The case of Cushing and Wolbach (1927) has been repeatedly quoted as a proven example of this process of maturation. In this case a biopsy of the extraspinal extension of a "dumb-bell" tumour demonstrated neuroblastoma. Ten years later the intraspinal extension was removed by Cushing and proved to be a benign ganglioneuroma. This has been interpreted as meaning that the intraspinal extension had undergone maturation. This interpretation is not necessarily correct, because it is well known that malignant and benign areas can co-exist in the same tumour. It seems more likely that the malignant tumour undergoes self-destruction by haemorrhagic necrosis, which in this case was induced by the biopsy. Whether or not one may accept the possibility of spontaneous cure is of more than theoretical importance. The tendency in recent years has been to treat these patients by radical methods even in the presence of metastases, and radical treatment might be withheld if spontaneous cure is considered to be even a remote possibility.

In the series reviewed there were seven cases of paraplegia. This may be spastic or flaccid, and the type of paralysis may be of some prognostic significance. Spastic paraplegia results from cord compression which may be due to a primary "dumb-bell" tumour, as in the case quoted above. A similar case is reported by Elefant, Jeklerova and Lesny (1955) in a baby of seven months, in whom the paraplegia was associated with a large paravertebral tumour, and the whole tumour was malignant. The tumour was treated by partial excision and post-operative irradiation. The child was reported to have survived for two years without recurrence and with considerable recovery of function. The cause of flaccid paraplegia is suggested by the post-mortem findings in Case 1. There was extensive involvement of the paravertebral glands with contiguous extensions within the spinal canal. The spinal cord was destroyed from the level of the fifth thoracic vertebra downwards. It seems that the cord lesion had resulted from interference with the blood supply of the cord, as there was no sign of cord compression.

\section{SUMMARY}

1. Neuroblastoma is a disease that may concern the orthopaedic surgeon closely.

2. Six such cases are reported.

3. Early diagnosis may be difficult, but can be achieved if the condition is suspected and an adequate investigation is carried out on suspicion alone.

4. The prognosis in these patients is still poor, but might be improved by a vigorous combination of surgery, irradiation and chemotherapy. The recent advance in treatment with vitamin B 12 may improve the prognosis substantially.

I am most grateful to Mr Charles Gray, at whose suggestion this paper was prepared, for his assistance in its preparation and for permission to publish five of the cases reported. I am indebted to Professor Ian Aird, Professor C. V. Harrison and Mr W. H. Stephenson, of the Postgraduate Medical School, Hammersmith Hospital, and also to Dr Martin Bodian, of the Hospital for Sick Children, Great Ormond Street, for their helpful advice and criticism. My thanks are due to Dr L. H. Walter, of Hammersmith Hospital, for permission to publish Case 3; to Dr H. Caplin, of the Connaught Hospital, for the photomicrograph in Figure 2; and to Miss R. McCullough, of the Photographic Department, Hammersmith Hospital, for preparing the illustrations. 


\section{REFERENCES}

Bodian, M., and White, L. L. R. (1953): Preliminary Observations on the Treatment of Neuroblastoma with Vitamin B 12. Annual Report of British Empire Cancer Campaign, 31, 174.

Bodian, M., and White, L. L. R. (1954): Neuroblastoma. A General Review. Report of British Empire Cancer Campaign, 32, 195.

Bodian, M., and White, L. L. R. (1955): Neuroblastoma and Vitamin B $\mathbf{1}_{\mathbf{1 2}}$ Therapy. Report of British Empire Cancer Campaign, 33, 186.

Bodian, M. (1956): Eighth International Congress of Paediatrics, Copenhagen.

Bodian, M. (1957): Personal communication.

Charache, H. (1954): Neuroblastoma. A Report of Ten Cases and Review of the Literature. American Journal of Surgery, 87, 545 .

Cushing, H., and Wolbach, S. B. (1927): The Transformation of a Malignant Paravertebral Sympathicoblastoma into a Benign Ganglioneuroma. American Journal of Pathology, 3, 203.

Elefant, E., Jeklerova, J., and Lesny, I. (1955): Rückenmarkskompression im Säuglingsalter. Annales Paediatrici, 184, 253.

GoldRING, D. (1951): Neuroblastoma Sympatheticum with Metastases. Report of a Case with Apparent Recovery. Journal of Pediatrics, 38, 231.

Gross, H. (1955): Ein kasuistischer Beitrag zum Neuroblastoma sympathicum. Wiener klinische Wochenschrift, 67, 681.

Hansen, P. B. (1953): Sympathicoblastoma of the Adrenal Medulla with Osseous Metastases. Acta Radiologica, 40, 500 .

HaRnett, W. L. (1952): Survey of Cancer in London. London: British Empire Cancer Campaign.

ImmermanN, E. W., and Compere, E. L. (1954): Bone Metastases of Neurogenic Tumors of the Sympathetic Nervous System in Children. Quarterly Bulletin of the Northwestern University Medical School, 28, 138.

Koop, C. E., Kiesewetter, W. B., and Horn, R. C. (1955): Neuroblastoma in Childhood. Survival After Major Surgical Insult to the Tumor. Surgery, 38, 272.

Oberkircher, O. J., Staubitz, W. J., and Parmenter, F. J. (1953): A Clinical Study of Neuroblastoma. Journal of Pediatrics, 43, 177.

Phillips, R. (1953): Neuroblastoma. Hunterian Lecture. Annals of the Royal College of Surgeons of England, 12, 29.

Poore, T. N., Dockerty, M. B., Kennedy, R. L. J., and WAlters, W. (1951): Symposium on Surgical Aspects of the Cancer Problem-Abdominal Neuroblastomas. Surgical Clinics of North America, 31, 1,121.

Reiquam, C. W., Beatty, E. C., Jun., and Allen, R. P. (1956): Neuroblastomas in Infancy and Childhood. A.M.A. Journal of Diseases of Children, 91, 588.

Uhlmann, E. M., and Essen, C. von (1955): Neuroblastoma (Neuroblastoma Sympatheticum). Pediatrics, 15, 402.

Willis, R. A. (1953): Pathology of Tumours. Second edition. London: Butterworth \& Co. (Publishers) Ltd. Wittenborg, M. H. (1950): Roentgen Therapy in Neuroblastoma. Radiology, 54, 679. 